\title{
The study of the weather as a branch of nature knowledge.
}

\author{
Marion I. Newbigin D.Sc. (Lond.)
}

To cite this article: Marion I. Newbigin D.Sc. (Lond.) (1907) The study of the weather as a branch of nature knowledge. , Scottish Geographical Magazine, 23:12, 627-648, DOI: $10.1080 / 00369220708733802$

To link to this article: http://dx.doi.org/10.1080/00369220708733802

曲 Published online: 27 Feb 2008.

Submit your article to this journal $₫$

Џ Article views: 8

Q View related articles ๘

Citing articles: 2 View citing articles 5 
Protectorate which could not be reached directly from the sea or from some region of similar status to its own. Moreover, the railway which will ultimately traverse this country from end to end is a continuation of the great Trunk Line of South Africa. There are thus, no doubt, considerations of great weight on either side, and we have perhaps cause to be grateful that, for the time being, Rhodesia is still in the possession of the Chartered Company, and that there is no need to settle the difficult question of its future distribution and administration in a hurry. The system of extending the bounds of Empire by the agency of Chartered Companies is open to many objections. There has been much in the methods of this particular Company, especially during its earliest years, which it is impossible to regard with approval. But the British South Africa Company has at least two great claims on our gratitude. It has kept a large and valuable portion of the Dark Continent under the British flag, and it has built up, in a remarkably short space of time, an administration which, if far from perfect, is at least competent, honest, and humane. Government by means of a company is necessarily a transient form of government. But in the case which we have been considering, it is a valuable stop-gap, valuable in maintaining a tolerable condition of affairs and affording time to work out with deliberation, and with a fuller knowledge than we yet possess of all the conditions of one of the least explored of habitable lands, the best permanent arrangements for its welfare.

And now I see that, starting from certain wide general considerations, I have been led to dwell, at perhaps excessive length, on a single, limited, and remote, though not unimportant or uninteresting, problem. But I venture to hope that in my method of approaching it I may to some extent have illustrated my main proposition, which is the inextricable association of your science with the art of statesmanship, and that in any views which I have propounded or suggested, be they right or wrong, I may at least not have offended against the spirit of scientific geography.

\title{
THE STUDY OF THE WEATHER AS A BRANCH OF NATURE KNOWLEDGE. ${ }^{1}$
}

\author{
By Marion I. Newbigin, D.Sc. (Lond.). \\ (With Illustrations.)
}

Is endeavouring to suggest to you methods of studying the weather in schools as a part of nature knowledge, it may be well to begin by considering very briefly the aims which should inspire a course in nature study, for our methods will be naturally largely influenced by our aims. The object of such a course is, I take it, twofold. We want in the first

I A lecture delivered to a class of teachers in connection with the University of Aberdeen on May 11, and also at the Outlook Tower, Edinburgh, on October 30, 1907. 
instance to train the powers of observation and develop the intelligence, with the view not only of making better citizens, but also of increasing the happiness of life; and in the second place we want to give an insight into the methods of science. To show that the methods of science are everywhere in essence the same, and to suggest that; owing to the fact that the further scientific research is carried, the more obvious it becomes that nature is orderly and uniform, and that there are therefore few series of phenomena too trivial to be worth study by some one-these in my opinion are points of great and increasing importance. Again, even elementary education is incomplete unless it succeeds in imparting some flavour of real enthusiasm for science, and that for two reasons. First, because the time when scientific pursuits could be regarded as a luxury for the few has passed, and the stability of the modern community depends, literally and absolutely, upon a widespread sympathy with the aims of science, if not upon a widespread knowledge of its contents. We must "educate our masters" if we are even to hold our position as a nation. The conditions of modern life make it impossible for the scientist, even if he would, to hold himself contemptuously aloof from the rest of the community; he must explain himself sufficiently to justify his continued existence. As a mere matter of domestic policy, nature study in schools is thus justifiable. In the second place, we have also to remember that with cheap literature and the spread of public libraries, the results of scientific research are becoming available to the general public in a way to which in past generations there was no parallel. Take for example the case only of a public library. In Edinburgh, not so many years ago, in spite of the abundance of scientific societies, the great bulk of the citizens might live and die without ever having seen a purely scientific journal, hardly perhaps even a purely scientific book. Now they are taxing themselves in order that on the tables of the Reference Room of the Public Library all the leading scientific journals may be spread out, and that the shelves of that library nay contain a good selection of modern books of science, which are there not only for the use of the citizens, but for that of any sojourner within the city. Surely no child, therefore, should be permitted to leave school without a knowledge of the alphabet of science, without some appreciation of the value of the heritage to which he has been born and of the best ways of utilising this heritage. If, as we are beginning to realise, the town child should have a general knowledge of his native town, of its buildings, its traditions, its mode of government and so on, he should surely have also some knowledge of the patient, continuous, self-denying work being carried on there and elsewhere in the name of science. Even from the purely scientific point of view this is desirable; for example, there can be no doubt that if the last generation of citizens had been rationally trained in the study of the weather, the Ben Nevis Observatory would never have been closed.

If, however, I am right in thinking that our aim in nature study should be rather to arouse interest than solely to instruct; if we are to look to the future rather than to the immediate school life, we reach the important corollary that we must from the first resist the temptation to 
be thorough. Personally, I should be disposed to say-don't be afraid to be scrappy. We may lay it down as an axiom that it is not possible, even if it were desirable, during the short school life, to teach botany, zoology, astronomy, meteorology and a dozen other sciences properly, and one should be very careful not to make the attempt. Be content to open doors, to give peeps of attractive vistas. Personally, I am sometimes appalled on reading the innumerable little books on nature study which appear in such numbers nowadays, and in reflecting on the risk which an incompetent person runs of utterly sickening his pupils with such books. One wants to aim simply, I think, at giving the child the impression that there is a great deal of interest in, for instance, the weather, or the common plants, and if possible - and on this I should lay great stress-of at least hinting at the means which exist for the further study of these subjects in the form of local or general societies, of reference libraries, of museums and so forth, so that if possible, at the critical stage when compulsory school attendance ends, the pupil may have interest enough to read or to observe for himself. But above all things, I should say, beware of attempting to gather fruit, in the form of examination results, before there has been time for a full root-development.

When we come to practical detail, I suppose most of you, as practical teachers, have felt that the supreme difficulty is to find what we may call a jumping-off point. I heard the other day an interesting story of a little girl who objected strenuously to going to school because, as she said with much force, "They don't teach me anything I want to know." This is probably a condition that frequently occurs, but in the teaching of such subjects as arithmetic and spelling we have behind us the driving force of parents and relatives, who say, with a truth that even the child recognises, that adult life is impossible without a certain amount of knowledge. 'In nature study in general we have not as yet this advantage, and have even to allow for the fact that the parent in the background is probably saying, "Tadpoles and dandelions are all very well, but that won't help you to earn your living." It is therefore very important to include in the course subjects about which the child does want to know, in which there is an initial interest to help us over the drag at the start. Now the weather is our basal subject of conversation, interests us at every turn of life, and as even the child feels this interest, the subject is one well worthy of the attention of teachers of nature study. Again, the uncertainty of our weather has become a proverb, the difficulties of forecasting not less so, and yet when we study weather in detail we find that, although we can say very little as to the possible weather next week, and almost nothing as to its probable course next month, yet the annual series of changes which make up the climate of a locality take place in orderly sequence, and almost all the elements of the total are more or less fixed and constant. The fact that from one point science means the finding of order in apparent chaos may thus be well brought out. One must not also forget that the child is eminently practical and utilitarian, and we are not only all naturally interested in weather, but in a maritime country it is of great practical importance. In a coast town like Aberdeen one has the coastguard stations as an 
evidence of this practical interest, and one can even hope to show that coastguard station, Nautical Almanack, and Meteorological Society form a sequence, illustrating the fact that science is merely enlightened and developed common sense and common experience.

How should we begin to study the weather? One would naturally, I think, begin with the common facts of daily experience, and would point out that what primarily interests us is the changefulness of the meteorological conditions. The temperature may be high to-day and much lower to-morrow, the air may be calm one day and in rapid movement the next, dry at one time and saturated with moisture at another, while the sky may be clear or covered with the clouds which portend rain. In other words, the most obvious variations are those in the temperature, the humidity and amount of movement of the air, and in the condition of the sky. Of these variables, one which can be very readily observed is that of the direction of the wind, and our senses enable us also to appreciate with a certain general accuracy its amount. Two facts then about British weather it is very easy to observe, first, that calms are somewhat rare, or in other words that our climate is predominantly windy, and second, that winds of a westerly direction predominate. The direction of growth of trees in exposed situations, the arrangement of shrubberies, etc., in parks and gardens, our common use of the term "west end," to mean the part of a town which is relatively smokeless, and thus to windward of the factories, are all ways in which one can drive home this fact. I need, however, hardly say that the class should be allowed to draw the deduction that west winds are commonest for themselves, on the basis of their own observations, before one proceeds to point out how it lies at the base of much of our common life.

Again, it is easy to lead the class to see that the air is in spring at least colder with an easterly than with a south-westerly wind, that our heaviest rainfalls usually come with westerly winds, and thus to prepare the way for the conclusion that there is some connection between the different phenomena which make up the series we call weather. Very little observation will, however, show that although the variables are connected, the connection is not very close. It is more likely to rain with a high wind than with a light one, the rain will probably be heavier if the wind be westerly than if it be easterly, a south-west wind means generally a warmer day than a north-east one, and so on : one can draw up a series of probabilities, but they will not be more than probabilities There is some connection, but not a very close connection, between these different factors, and the probabilities point to the conclusion that there is some other variable element which we have not considered which is affecting all the others. This element is of course pressure, and one should, I think, endeavour to drive home the fact that while, within reasonable limits, our senses give us no information as to the variations of pressure, yet these variations when measured by a barometer give us more information about the probable course of the weather than any direct observations we can make. To put the matter in another way, man, ever since he was man, has watched the sky and the clouds, has noted the direction of the wind, has distinguished between cold and heat, 
dryness and damp, but not until the invention of the barometer could he find a rational connection between these different phenomena. Now the most weather-wise individual without a barometer is no match - for one less sagacious, but·furnished with the information. which that instrument only can give. Without labouring detailed explanations of the barometer, I should be disposed to tell stories of Toricelli and Pascal, of de Saussure on Mont Blanc, and of the latest Arctic and Antarctic explorers, in the hope of stimulating the imagination, of driving home the great truth that before so commonplace an occurrence as the flying of storm-cones at a coastguard station can take place, countless generations of men must have lived and worked. Our nature study does little if it does not make clear into how great a heritage every child of a civilised nation is born, if it does not drive home the lesson that not only the great men but all the unknown generations of patient toilers have, in their degree, contributed to build the temple of knowledge, have helped to make life easier for us their heirs.

Some form of barometer is so common an article of furniture that there should be no difficulty in arranging that some members at least of the class should read it every day and record their readings over considerable periods of time. Where this is feasible I should be disposed to recommend that the pupils, at least sometimes, be induced to go and read the barometer at a coastguard station, or at any other place where there is a publicly exposed instrument, for this adds greatly to the importance of the readings in their eyes. It is a very simple matter to plot the readings on squared paper, so as to obtain a curve, and the pupils should be made to add to each day's readings a note on the direction and amount of the wind, the

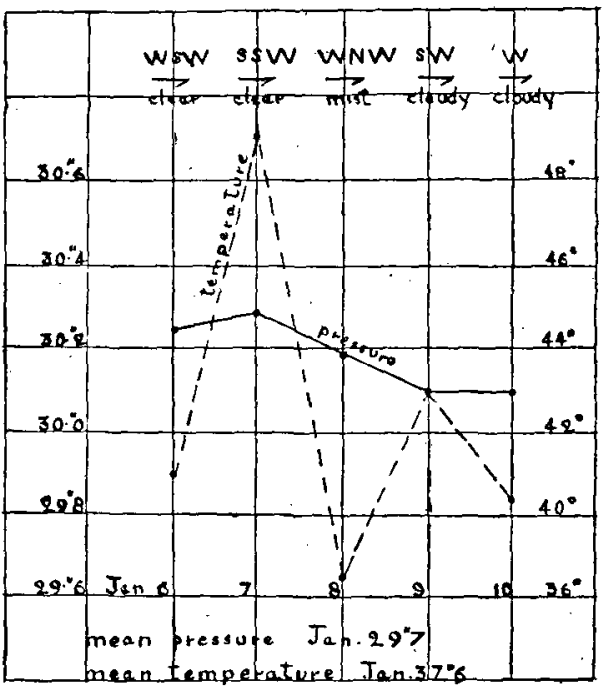

FIG, 1. condition of the sky, occurrence of rainfall, and so on. I show here three sets of readings chosen for three periods during the last winter. The figures are taken from the meteorological maps furnished by the Meteorological Office daily to the Times.

I have taken first the period from Sunday, January 6, to Thursday, January 10, inclusive (Fig. 1). It will be remembered that this was a period of fine dry weather which followed the stormy period with which the year opened. As the diagram shows, the barometer varied during the time from 30.1 inches to 30.3 . Now, as I have shown in the diagram, 
the mean barometric pressure in Aberdeen during January is only $29 \cdot 7$ inches, so that the barometer was high during the period, and varied comparatively little, though on the whole it was falling. During the whole period the winds were light, swinging to south and to north of west. Further, if we had allowed the children to add notes on the temperature as determined by their own feelings, we should probably have found that while they were all agreed that Monday, January 7 , was warmer than usual, and Tuesday, January 8 , was much colder, the opinions about the other days would vary. This would naturally lead to the deduction that though we can estimate temperature by our senses, yet our estimates have only a very generalised accuracy, and that they require to be checked by a thermometer. This can be bought so cheaply that there is no excuse for not having one outside, to be read in connection with the barometer. If the readings of this were added to the barometric readings, and compared with the mean, we should at once perceive that the temperature had been high throughout the week, and that it was highest with a south-westerly wind and lowest with a north-westerly wind. This would naturally lead to the display of an

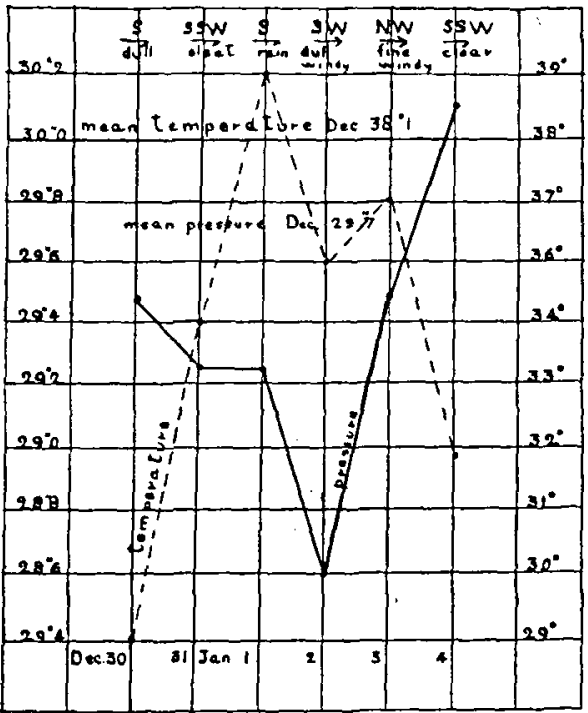

FIg. 2. orographical map of the British Islands, and the demonstration of the fact that in order that the south-west wind may reach Aberdeenshire it must blow over not only the warm seas to the south, but also over the high ground of the Grampians. As the moving current of air rises over these mountains it expands, cools, and precipitates much of its moisture; as it descends from the crest to the low ground it is warmed and dried by compression, and therefore the winter temperature of Aberdeenshire, where south-west winds largely predominate, is higher than it would otherwise be. In other words, the wind sweeps down from the Grampians with something of a foehn effect.

To compare with this period I have taken another period just preceding it (December 30 to January 4), which illustrates quite another type of weather (Fig. 2). Throughout this period the barometer first dropped rapidly and then rose suddenly. As it dropped the thermometer rose, and as it rose the temperature fell. With the low barometer stormy winds occurred, and the week was also distinguished by precipitation, which took the form of sleet, snow, rain, etc., according to the tempera- 
ture. A point to which one would draw special attention is the fact that the boisterous winds veered from south-west to north-west, and then as the stormy period passed by, swung round to south-west again.

At the risk of wearying you $I$ add a third chart illustrating a different series (Fig. 3). During the period January 21-25 the barometer was very high throughout, but you will notice here that, while the temperature fell with a rise of pressure, it fell still further towards the close of the period with a fall. This brings out the fact that there is no necessary direct connection between changes of pressure and changes of temperature. In this period winds with an easterly component occurred, and these were accompanied by a comparatively low temperature. An interesting fact is the occurrence of a comparatively low temperature on January 24 accompanied by a south-west wind, usually our warmest wind.

Observations of this kind should be taken over a considerable period, and the scholars should be taught to plot them after some fashion similar to that shown. As shown on the diagrams, pressure and temperature may be plotted on the same square, and notes on wind and the state of the sky added. As to the deductions to be drawn, the first and most obvious is, of course, that a high, steady barometer means settled weather, accompanied by light winds and little precipitation. With such a barometer the temperature may be high in summer and unusually low in winter and spring, but this varies mich with the quarter from which the wind blows. On the other hand, a low or changing barometer means unsettled, more or less rainy weather, often with strong winds. It is easy to show that the greater and more rapid the drop the stronger the wind, and that frequently a heavy rainfall precedes the drop of the barometer to its lowest point, and precedes also the development of stormy winds. It is also not difficult during much of the year to find periods which exemplify the fact that, while a high barometer is often a steady barometer, varying little for several days, a low barometer is always unsteady, and

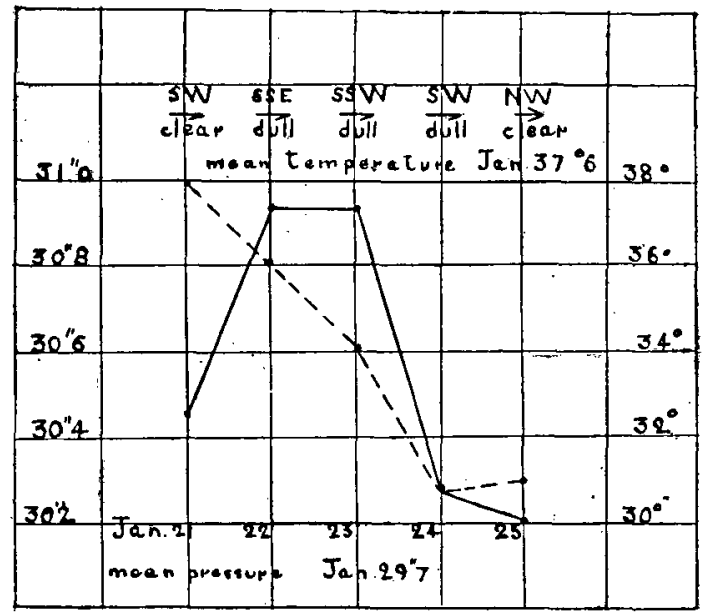

Fia. 3. the greater the drop the more rapid the return to a more normal position. It must always be a question for the individual how far it is necessary to explain the meaning of the barometer and its graduation, but in my opinion it would be a great mistake to do this at too early a stage. After a good many curves had been constructed it would of course be

voL. XXIII. 
easy to explain the meaning of the term "mean height," and one might draw a line across the page to show the mean height for the month or for the year. The annual mean for Great Britain being 29.9 inches (Aberdeen 29.85 inches) it is convenient to allow the children to regard all pressures much below 29.9 as low, and all those much above as high. In addition to the obvious points named above, one might without difficulty get them to see that winds with a westerly component are by far the commonest with us, and that generally the south-west wind, which is a comparatively warm wind, is commoner in winter, while in summer the cooler west or west-north-west wind tends to predominate. If the observations are begun in winter it is also not difficult to show that frequently, though not invariably, in stormy weather the wind veers from south-west to north-west, and back to south-west when the storm is past, and that a rise of temperature frequently precedes a storm, and a fall the clearing and settling of the weather.

I should be disposed to continue the observations for some time at this level, in order to accustom the pupils to take an intelligent interest in atmospheric phenomena, and to realise the basal facts as regards variations in pressure and temperature. The temperature observations should be continued long enough, in spring and autumn especially, to show the slow upward creep in spring to the July maximum, and the equally slow downward creep to the January minimum. Pressure on the other hand reaches its maximum in May or June when east winds predominate, and its minimum in the region of Aberdeen in the stormy month of January. With or without the help of actual observations of rainfall one would try to lead the class up to the deduction that, if most of our rainfall comes with high winds or storms, and these come with periods of low pressure, then the months of highest pressure will be the months of least rainfall, and the months of lowest pressure will be the months of highest rainfall. I should lay great stress upon the necessity of leading up to deductions of that kind, because, as already pointed out, the great value of the study of the weather is that it serves to show that science nieans finding order in what looks like chaos, and there is a widespread impression that the amount and time of fall of our rainfall are phenomena wholly outside natural law.

Sooner or later, however, one wants to go further than this, and to show in detail how the minor constantly occurring fluctuations of weather in our country are all parts of a great series of phenomena affecting vast tracts of the earth's surface.

In the first place, the analogy of the punctured bicycle tyre or the open gas tap will enable one to explain that air, or any gas when free to move, tends always to flow from a region of high pressure to that of low. With this as a basal foundation, one may allow the scholars to draw for themselves the deduction that if at Aberdeen there is a strong wind blowing, and the barometer at the same time shows that the pressure is low, then we know that the air forming this wind is flowing from some region of high pressure into the area of observation. Let us take, for instance, the conditions prevailing on January 25 as shown on the accompanying map (Fig. 4): In passing, one may point out that such a simple form of 
map is readily drawn on the blackboard. Such maps are published daily in the Times, and also by the Meteorological Office, and a first lesson oi such a map would naturally be given after barometric readings have been taken for some time. On showing the map, one would simply point out that great numbers of people have for the particular day been also reading their barometers, and that the lines are drawn through places where the pressure was equal at the time of observation. On the particular date at which this map was drawn, the pressure was high off the west coast of Ireland, 30.5 inches, and comparatively low, $29 \cdot 9$ inches, off the coast of Norway. The result was that a strong wind appeared off the coast of Aberdeenshire, this wind having a northwest direction. Some acute observer would doubtless at once point out that the analogy of the bicycle tyre is insufficient, because obviously the air is not moving direct from the region of high pressure to that of low. The reason is, of course, the fact that the earth is a rotating body. How

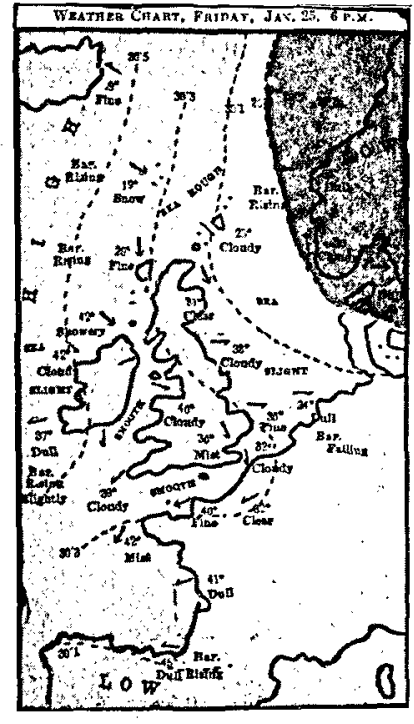

FIG. 4.1 far it is possible to explain the cause of the resultant deflection to an elementary class is a difficult question, but it seems to me that in the first instance one should be content to emphasise the fact of the deflection. When the fact had been thoroughly grasped one might venture upon an explanation, but I should not personally be disposed to lay much stress upon it. The fact of importance is certainly that, in the northern hemisphere, if the wind is at your back, the lower pressure is at your left hand, or conversely that the wind blows roughly at right angles to a line joining the regions of high and low pressure. In other words, the wind is roughly parallel to the isobars, or lines of equal pressure. This, known as Buys-Ballot's law, should be perfectly familiar, and the class should be able to answer without hesitation such questions as:-If the pressure is low in the Hebrides and high over Denmark, what will be the direction of the wind in Aberdeenshire? If the wind is east at Aberdeen, where is the pressure high and where is it low $?$ and so on. The matter should be returned to at different periods until all the members of the class appreciate the fact that, when they know the direction of the wind in their own neighbourhood, they know something about the distribution of pressure in the surrounding regions.

When the pupils have become familar with rough weather charts drawn on the blackboard to illustrate the relation between pressure and wind, one would proceed to show what other points one may learn from such charts. Let us take one of those for one of the days in January which

1 In this and the following charts, the dark wash indicates low pressure, and the lighter ligh. 
we have already studied (Fig. 5). On January 2 , a day when the wind was fresh or strong over much of the British area, we find on the chart that

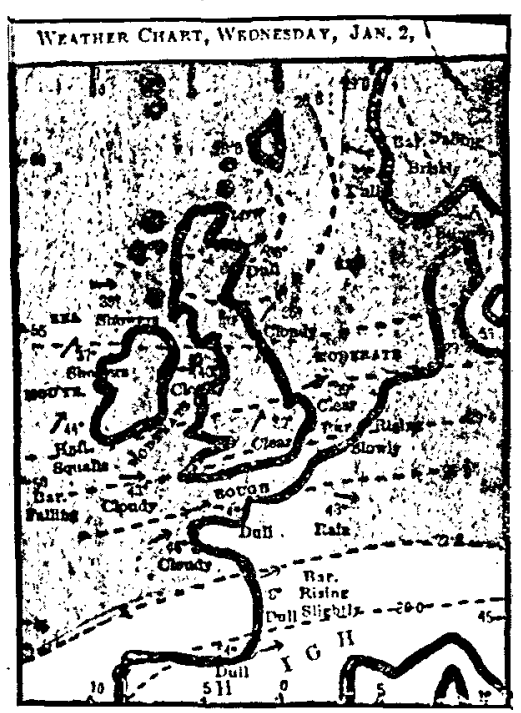

FIG. 5. the pressure at Aberdeen was only 28.6 inches, while in the south of England it was 29.4 inches. In other words, between Aberdeen and Hastings, a distance roughly of 450 miles, there was a difference of pressure of $\frac{8}{10}$ of an inch. That is, in travelling between these two places we should find that every 56 miles caused the barometer to fall $\frac{1}{10}$ of an inch. We express this by saying that on that day there was a northward gradient of $\frac{1}{10}$ of an inch in 56 miles. The result on the principles already discussed is that the wind was southwesterly to west at Aberdeen, and as the gradient is unusually steep, the wind was almost everywhere strong. The gradient posts on a railway cutting will help to make clear the meaning of the term gradient. One would also point out that a north or north-west gradient is the commonest one in Britain, or in other words, the air is, generally speaking, piled up to the south or south-east of England, and is thinner to the north or northwest of Scotland; and the result is that our winds are generally westerly in direction, the air travelling northwards being deflected to the right owing to the effect of the earth's rotation. With the conditions on January 2 we may compare those on December 30 , when the winds were light over the British area generally; the gradient was only $\frac{1}{10}$ of an inch in about 120 miles, that is, less than half that of Jan. 2, and was north-westerly rather than northerly, the result being that the southerly component of the wind was more marked. These examples serve to show that the intensity of the wind depends, other things being equal, on the amount of the gradient, a steep gradient meaning a strong wind. The weather map for almost any day will afford materials for a lesson of this kind, and will serve to drive home the fact that the local conditions are interesting, both because they are a' part of the whole, and because they enable us to draw certain conclusions as to the conditions existing in other regions.

As well as drawing charts on the blackboard, the teacher may very easily show the class how to construct these by giving them a blank map of Great Britain and a few barometric readings in addition to the local one, and then allowing them to draw lines connecting the places of equal barometric height, putting in a few arrows to show the theoretical direction of the wind. If such a map is made and compared with an 
actual weather chart, it will be seen that the local conditions may at any given spot considerably modify the actual winds.

When in this way we have succeeded in giving some general knowledge of the relations between the variations of the barometer and the amount and direction of the wind, we want to take some further steps in advance. Why does the barometer swing up and down? If the pressure, as a general rule, is higher in the south of England than in the north of Scotland, how is it that we have sometimes east winds in the north of Scotland? Why is the barometer sometimes steady for days, while at other times it oscillates continually? We want to encourage the asking of such questions. If the observations are begun during the colder season of the year, it is unlikely that they will be continued for long without including what the meteorologist calls a cyclone, and the opportunity may be taken for a general discussion of the meaning of cyclones. Instead, however, of beginning with a definition which would probably entirely fail to interest the class, it is, I think, possible to devise means of getting at the facts indirectly. The observations of the barometer have shown us, so far, that a falling barometer generally means wind, and a rapidly falling barometer strong wind, because the air rushes in to fill the space indicated by the low glass. Let us take the period from December 30 to January 3 as an example of a period of low and changing barometer (see Fig. 2, p.632). You will notice that, as has been already pointed out, this was a period also of strong and changing winds. Now, on the principles already discussed, this means that the region of low pressure is changing its position. For example, on January 2 the wind was south-west at Aberdeen, therefore the pressure must have been low to the north-west of Scotland. On January 3 the wind was northwest, therefore the pressure must have been low in the region of Scandinavia. We shall find by observation that stormy periods are always periods of changing winds, and we therefore draw the first deduction that storms mean the existence of an area of low pressure which is continually changing its position. Once again, a further examination of our diagram will show that on this occasion the barometer began to fall distinctly before the storm developed itself. The drop was at first slow, and gradually increased in rapidity as the storm approached. If we had been in communication with a school on the west coast of Scotland, we should have found that the barometer there dropped before ours did, and if we had been also in communication with a school on the west of Ireland, we should have found that their barometer fell still earlier, and in both cases the earlier fall meant an earlier development of stormy winds. We might then sum up by saying that during the period December 30 to January 4 a storm swept across Ireland, over Scotland, and then across the North Sea to Norway. But we could express the same thing in other words by saying that a wave of low pressure swept over this region. Continued observation would then convince us that when there is a very low barometer at Aberdeen this is not an isolated phenomenon. As a general rule, before the barometer drops at Aberdeen it has already dropped some point to the west of us. After it has turned to rise at Aberdeen, it is still falling at some point 
to the east of Aberdeen. Such moving areas of low pressure are called cyclones, and as a general rule cyclones reach us from some point to the west and travel to some point to the east. As they travel to the northeast or east, the cyclonic areas gradually die away.

The exact sequence of events may be more clearly made out by the study of the weather maps for the period. On Tuesday, January 1, a very well defined approximately circular area of low pressure lay over the west coast of Ireland, which on the two following days gradually passed over towards Norway (see Fig. 5, p. 636). Now into a circular area of low pressure of this kind the winds swing counterclockwise, therefore when the cyclone passes to the north of the point of observation the wind will veer from south-west to north-west, returning to south-west as the influence of the storm area passes completely away. It is easy to realise that this must be so if one thinks again of Buys-Ballot's law. If the area of low pressure is to the north-west of the point of observation, then by this law the wind will be south-west. When the area of lowest pressure shifts to the north of the point, the wind will be west, while as the area of low pressure passes over to the north-east the wind naturally becomes north-west. The maps show this well, but I should urge that the pupil's attention be repeatedly drawn to the fact of its occurrence in the case of storms before one offers an explanation. If difficulty is then found in explaining the shift, the simplest way of making matters clear is to make one pupil represent the moving cyclone while another member of the class revolves so as to keep his left hand to the moving boy. The wind is always in his back. The attention of the class should also be drawn to the fact that the temperature usually rises as the cyclone approaches, and heavy rain often precedes the fall of the barometer to its lowest point. As the glass turns to rise, the weather clears, becoming finer but colder. To put the matter in another way-if the glass is steadily dropping, while the temperature is mild, it is probable that there will be rain, followed or accompanied by strong winds. These points are very easily observed. If the centre of the disturbance passes through the point of observation, then its passage may be marked by a squall accompanied by heavy rainfall, after which the glass begins to rise. Of this, the "clearing shower" as it is called, we had some pretty examples last winter. It not infrequently happens, however, that the whole series of phenomena does not present itself in so typical a form as in the particular case illustrated. Especially in winter time it sometimes happens that one depression follows hard on the heels of another, and thus the rise of the barometer and the fall of temperature are more or less marked. If after the passage of one cyclonic area the temperature rises suddenly, then another disturbance may be expected.

I have chosen for this first example a disturbance whose centre passed very near Aberdeen, so that its effects were well marked there. But there are frequent winter cyclones which pass along other tracks and affect the Aberdeen area in quite another fashion.

I have represented an example on the accompanying diagram (Fig. 6). You will notice that on November 4, 1906, the glass at Aberdeen was 
low and falling, the temperature high, the sky overcast, and the wind easterly and boisterous. On Monday, November 5, the glass had fallen much further, the temperature had fallen with a backing of the wind to the north-east and the rainy conditions continued. By Tuesday the barometer had risen and the temperature had markedly fallen with a further backing of the wind to the north-west, while at the same time the sky cleared. The weather maps show that the cause of these changes was a very well marked depression which swept up from the Bay of Biscay, affected the south of England and the Channel strongly, and gradually died away as it reached the North Sea. In this case, the area of low pressure passed to the south of the point of observation, and, as may be readily understood, on reflecting that if the left hand be made to follow the moving centre the wind will always blow on the back, the wind necessarily changed from southeast to east, north-east and finally

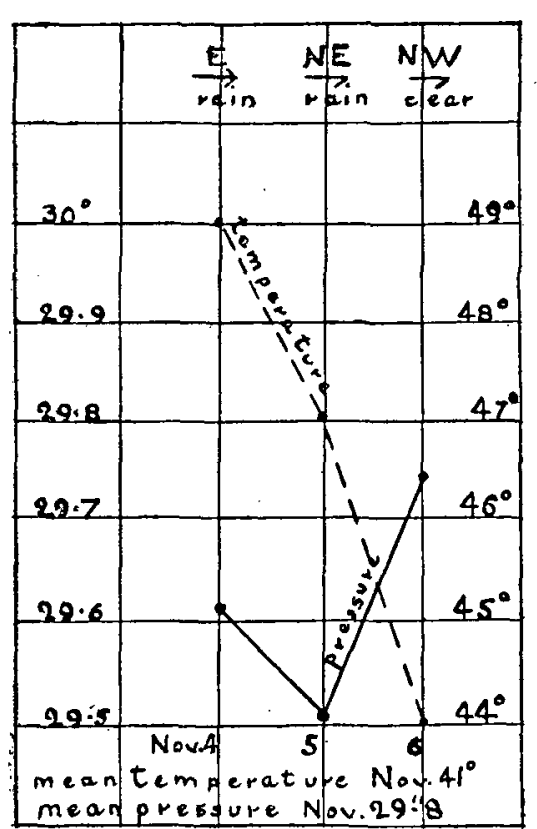

Fig. 6. north-west. Now in the case of the earlier observations, the point of observation was usually such that the majority of the cyclones passed to the north of the observer, and therefore the change from south-west to northwest was regarded as the normal one and was called "veering," while the other series of changes from south through east to north-west was regarded as abnormal and was called "backing." But again I should say, do not attempt such explanations until after the facts have been observed, and seize the points of human interest as the basis of the lesson. Let the pupils, for example, deduce for themselves the conclusion that when there is a big winter storm in the Channel, then the wind at Aberdeen changes from a south-easterly direction to a north-westerly one, but on the other hand, when there is a storm off the north or north-west of Scotland, the wind swings from south-west to north-west. Once they have observed this for themselves they will, I think, be delighted to have the reason shown to them.

Throughout the winter months in any normal winter both types of cyclone occur only too abundantly, and the class should be taught to pick out the more distinct of them from their regular series of observations, and draw their own conclusions as to their path across the country. At the end of the winter one might show the class a storm-chart, or even allow them to construct such a chart on the basis of their own observations, to show the normal tracks of the winter storms, and 
to emphasise their frequency off the west of Ireland and Scotland, in the south of England, and so on. There is of course no reason why, at any rate at first, the academic term cyclone should be employed at all. That a storm is in essence a moving area of low pressure into which the strong winds blow in the reverse direction to the hands of the clock, and which usually reaches us from some point of the western Atlantic, is all that is needed in the first instance. Later, when meteorological maps had become thoroughly familiar, if this stage were reached, it would be time enough to point out that while all our storms are due to cyclones, we cannot tell if an advancing cyclone is or is not sufficiently well developed to produce a true storm. Some meteorologists recommend that the pupils be ultimately allowed to attempt forecasts for themselves. Personally, I should be disposed to be content if I succeeded in suggesting how it is that forecasts are possible, to the limited extent to which they are as yet possible. The suggestion has been made for America, where the weather is perhaps somewhat more dependable than here.

One would also, of course, correlate the results both with the history and geography lessons, and point out the connection between the history of Britain and the storm-tracks which all but engirdle it, the lessons which the race has learned in those tempest-tossed narrow seas, the meteorological meaning of the Channel Tunnel scheme, which is so largely influenced by the Channel cyclones, and so forth. All these are points which would certainly interest the class, as being subjects in which their elders are also interested, and in which really important people like coastguards, sailors, and so forth are concerned

At the close of a winter of such carefully kept observations one should be able to get the class to make for themselves a series of deductions like the following:-

We had this winter a number of storms (number stated) in which the wind veered from south or south-east to south-west and then to north-west. It was warm and rainy at first when the wind was slowly shifting from south to south-west and while the glass was falling, but when the glass began to rise and the wind went round to the north-west it was colder and drier. We had another series of storms in which the wind backed from east through north to north-west. There was not then generally so much rain before the barometer fell to its lowest point as in the other case, but after it began to rise the weather was again colder and clearer. These deductions having been made, one could by the help of weather maps say something on the general subject of cyclones.

If, by the help of a home-made rain-gauge, one had also measured the rainfall, it would be possible to make clear the fact that the rainfall is usually heavier when the centre of the cyclone lies to the north than to the south of the observer, and the other fact of interest that the greater part of our rainfall is cyclonic, that is, would give definiteness to the common fact of experience that strong winds and rain generally go together with us. One might even succeed in reaching the conclusion that, as we get most rain when the cyclone passes to north-west of us, then the wettest parts of Britain will be those which have most storms 
passing them in this direction, i.e. will lie to the west and north-west. This fact, taken in conjunction with the fact that the mountains of Britain lie to the western side, explains the peculiarities of the British rainfall. It seems to me that once the interest of the class had been aroused in meteorological phenomena, oceasional geography lessons which would bring out the peculiarities of the climates of Britain would be probably greatly appreciated.

The making of maps to illustrate rainfall, isobars, storm-tracks, and so forth, would almost certainly be found more interesting than the ordinary types, and can be done very simply, while they will be much clearer if coloured.

But though, at any rate in winter, storms are only too frequent with us, other conditions also occur. Is there nothing to observe during a period of calm, settled weather? Let us look first at a diagram for such a period constructed on the basis of daily readings of barometer and thermometer (Fig. 3, p. 633). On Monday, Jan. 21, the weather was clear, the temperature normal, the pressure high, the wind south-westerly and light. On Tuesday the temperature had dropped, the wind had gone round to the SSE., the sky was dull, and the barometer had risen to a great height: On the next day (Wednesday, January 23) with a change of wind, the temperature had dropped still further, and the barometer was still very high. The reading marked is that for 6 P.M., but at ten o'clock in the morning in Aberdeen the glass was actually above 31 inches and only slightly below the "record" for the British Isles, while during the same day it apparently reached an actual "record"

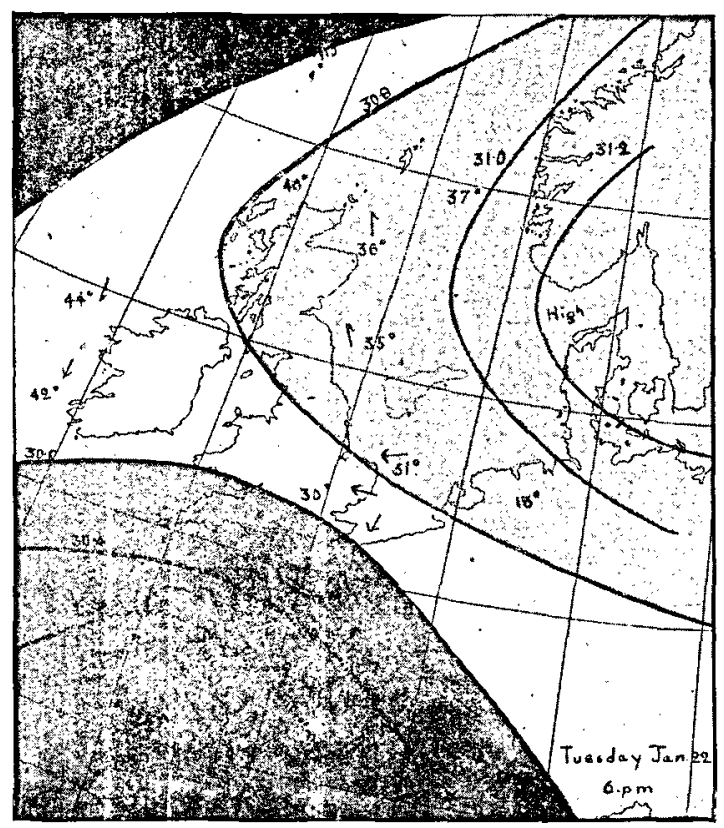

FIG. 7.

in Russia. Thursday showed a very marked drop of pressure as well as of temperature, and Friday an increase of wind, a further drop of pressure, and a slight rise of temperature. Throughout the whole period, as the diagram shows, the pressure was very markedly above the average, so that until its close the conditions were what is called anticyclonic. The weather charts make clear what was actually 
happening. On Tuesday, January 22 (Fig. 7), it will be seen that an area of high pressure embraced the south of Scandinavia, Denmark, and included the whole of Scotland and a large part of England. At the same time an area of considerably lower pressure occurred over the Bay of Biscay. Into the area of high pressure the winds were swinging in a clockwise fashion, and therefore with a prevailing eastern direction, which varied from pure east over the south of England to SSE. over the north-east coast of Scotland. Now the east wind in winter is sweeping across the cold snow-covered plains of Central Europe, and therefore it is much colder than the south-east wind which comes from the warmer parts of Europe. In consequence, you will notice that Aberdeen was then warmer than the south-east of England, and much warmer than Holland. Once again, while Scotland and the greater part of England were under the influence of the clockwise whirl of the anticyclone, Ireland and the seas off the south and west of England were under the influence of the counter-clockwise whirl of the region of lower pressure. As the gradients between the two regions are steep we find, first, that the Channel and ocean are more or less stormy, and second, because the ocean in winter is warmer than the Central European plain, and because the winds here are oceanic, that the temperatures at the west were much higher than those to the east. On the following day the anticyclone had spread more and more over Britain, pushing the area of lower pressure to the south, as it were, and the régime of easterly winds in consequence spread more and more over the south of England and over France, with the result that a wave of cold spread more and more over this region, while at the same time the warm region was being pushed to the north, so that at the Faeroe Islands it was very much warmer than at London. The temperature at Aberdeen was $34^{\circ}$ as compared with $28^{\circ}$ in southern England and $45^{\circ}$ in the Faeroe region. On Thursday the anticyclone showed signs of disappearing, and the weather was influenced by the appearance of a depression to the north. The presence of areas of high pressure over the west coast of Europe and over Ireland produced, however, cold and snow over much of the British area, especially to the south.

Apart from the special peculiarities of this period, we may deduce one or two general facts as regards winter anticyclones. First, the weather chart shows very clearly that an anticyclone to the north of any given spot means winds with an easterly component, which in winter and spring are cold and dry. They are cold because of their origin, and dry because they form part of an anticyclonic or descending circulation. It is these anticyclonic winds which tend to occur especially in spring, and which, because of their dryness, produce on most people a definite and disagreeable physiological effect. Although there is a popular superstition that they are commonest in east and north-east Scotland, the position of the anticyclones in the early part of the year is such that, in point of fact, they are commonest in the south-eastern part of England. Secondly, the chart shows that if an anticyclone is to the south or to the south-east of a given spot, the winds will have a westerly component, and the cold will be less than 
in places further south. In other words, it frequently happens during an anticyclone of southern position, that places to the north and northwest are considerably warmer than places to the south and south-east. I need not take up your time by pointing the effects of this fact upon the winter climate of western and north-western Britain, as compared with eastern and south-eastern areas. The diagram (Fig. 3), however, shows another point, and that is, that even apart from the east winds there is a tendency for the temperature in a winter anticyclone to be low. This is becattse the air sweeping out of an area of high pressure has been dried by compression, and such dry air allows radiant heat to pass through it very rapidly. During a winter anticyclone, especially in February or late in January, when the sun has considerable power, the almost windless air may feel comfortably warm during the day, but no sooner does the sun go down than rapid radiation begins, and we have the severe night frosts characteristic of winter anticyclones. The length of the winter night and the shortness of the winter day means relatively little absorption and very rapid radiation. A winter anticyclone then means clear, keen frost, with often cloudless sky and sunny days, and bitterly cold, starry nights. Further, as the ground radiates heat very rapidly, it usually happens that low-lying places, and especially narrow valleys, become clothed in a dense mantle of fog due to the cooling of the air nearest the ground below saturation point. This effect is greatly assisted by the calmness of anticyclonic weather, and is the reason why places slightly elevated above the sea and above valley floors are best suited for winter resorts. In the same connection one might point out that because over much of the continent of Europe the winter weather is typically anticyclonic, it is clear that winter resorts in the Alps, for instance, must be mountain regions and not in deep valleys, for there is not sufficient wind to sweep away the damp fog that accumulates on the bottom of the valleys. Speaking generally, anticyclonic periods are less well marked in Scotland, and especially in north-west Scotland, than in south and south-east Fngland, and the chart of storm-tracks gives us the reason. It shows that the climate of Scotland is strongly influenced by depressions arising from the region round Ireland, which,

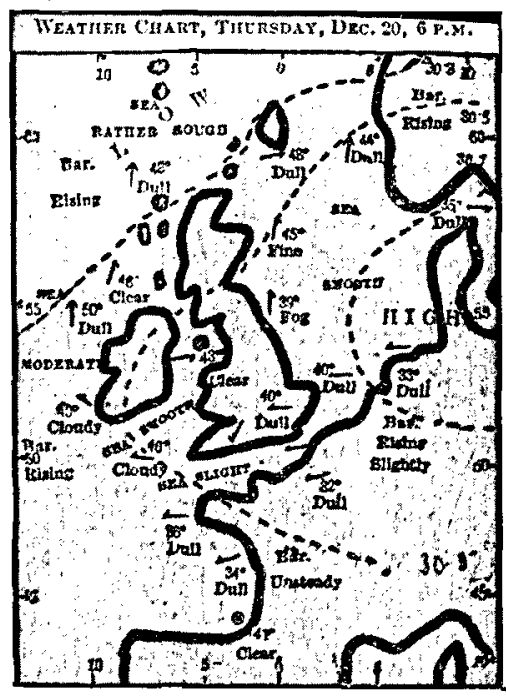

FIG. 8. as it were, push away the anticyclones.

The weather chart for December 20 (Fig. 8) shows another anticyclone, and it is again interesting to note how the position of the area of high pressure is chilling down the south of England and the greater part of 
France, while the western shores are comparatively warm. Again also, you will notice that Aberdeen is influenced by the western conditions, so that it is actually warmer there than in the south of England. On the other hand, on May 6, when there was a northern anticyclone over Iceland, the temperature at Aberdeen $\left(46^{\circ}\right)$ was $20^{\circ}$ lower than that of London $\left(66^{\circ}\right)$, which was influenced by an area of low pressure over Ireland.

Somewhat different conditions are shown by the weather charts at the end of March. It will be remembered that there prevailed then over the greater part of the British area a type of warm, calm, dry and sunny weather, unusually mild for the season. I show here the chart for March 21 (Fig. 9), which has some interesting features. The chart shows that over the greater part of England the weather is under the influence of an area of high pressure lying to the south. The winds were largely west or south-west, the temperature was high, and the sky clear and sunny. Ireland and much of Scotland, especially the west, was, on the other hand, under the influence of an area of low pressure lying near Iceland, and there causing storms. The influence of the cyclone was shown in the cloudy sky, and in the lower temperature off the north-west where the winds were west or north-west. Later, the anticyclone extended its sphere of influence, so that much of the British area was embraced by it.

These examples may serve to show that the anticyclonic condition is very different from the cyclonic. While in the case of a cyclone the air

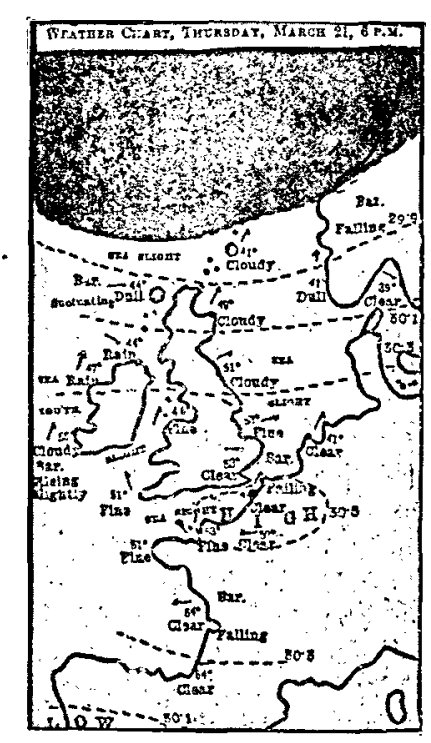

FIg. 9. streams in from the surrounding regions to fill up the central depression, in the case of an anticyclone it is streaming gently outwards, forming light winds which sweep round the centre in a clockwise spiral. Now in the case of the cyclone the entering air rises as it enters, and is thus expanded and cooled, often below the saturation point, so that we have the characteristically heavy cyclonic rainfall. In the anticyclone the air that sweeps out of the centre is replaced by descending air, which is thus warmed and dried by compression. The result is that an anticyclonic period is a period of characteristically low precipitation. Again, while a cyclone is a moving area, an anticyclone is more or less stationary, remaining until it is displaced by an advancing cyclone. The anticyclonic periods are thus periods of settled weather and steady barometer. In detail, however, the character of the weather during an anticyclone depends greatly upon the season, and upon its position. The very cold period of predominating east winds which occurred in the middle of April was, for instance, due to the prevalence of an anticyclone over the northern part of our area. 
In summer, from whatever quarter the light winds blow, they come from regions baked more or less in the summer sun. The nights are too short, in the early part of the summer, for much radiation to occur, and the long day means that the earth is baked in the welcome heat. The only disadvantage is that these periods are in summer apt to be periods of long-continued drought, for rain does not come until the anticyclone is displaced by the approach of a depression from the west. When anticyclones prevail comparatively late in the season, as in September, the rapid radiation and heavy dew at sundown is often very striking, and still later, of course, the warm days are often closed by a sharp night frost. The warm weather of the summer of 1906 was the result of a succession of anticyclones, the hot spell at the end of August being due to a well-marked anticyclonic system over western Europe. As a general rule, however, much of Scotland is less liable to anticyclones than the south of England both in summer and in winter, and as on the low ground a long-continued anticyclonic period soon becomes oppressive, we find that in summer many of the inhabitants of the south of England quit it for those parts of Scotland where they may feel the cooling effect of those slight cyclonic depressions which advance from the west and bring with them north-westerly or westerly winds and showers.

It will be seen from the above that there are few periods, either in summer or in winter, when it is not possible to give interesting lessons on the weather, and that by a judicious graduation and combination of observation and direct instruction it is possible to make the main points as regards cyclones and anticyclones clear to an elementary audience. For the sake of completeness, I should like to add a short discussion of the factors which determine the relative prevalence of cyclones and anticyclones in our area. This wider view of the subject cannot be so directly related to the pupil's own observations as the preceding, but it would, I think, afford material for occasional useful lessons. It is a fact of common experience that our winters tend to oscillate between two types:- the very cold, still, frosty anticyclonic type which, when it occurs, is almost always much better marked in southern England than in Scotland, and the stormy, warmer type when snow and severe continuous frost are rare, but when storms are frequent. Similarly, our summers tend to oscillate between the very hot, still type, with long drought, again not usually well marked throughout most of Scotland, and the more or less blustery, cooler, and more rainy type, which is more or less constant in the north-west. Now what has been already said will make it clear that this simply means, that on the whole cyclonic disturbances are more frequent, both in winter and in summer, across the northern and western parts of these islands than in the other parts. Again, if this is the case, then it is obvious that the mean barometric pressure must be lower to the north and west than to the south. I have already explained that this is so, and Dr. Buchan's maps bring out the point very clearly. ${ }^{1}$ In

I See Journal of Scottish Mreteorological Society, xi. (1898): 'The Mean Atmospheric Pressure and Temperature of the British Islands,' by Dr. Buchan. 
the colder months of the year the mean gradient is north-westward that is, the lowest pressures occur to the north-westward where the cyclonic areas most frequently pass. In the warmer months, on the other hand, when the paths of the cyclones are further to the north, the gradient becomes northward, that is, the isobars run approximately east and west. In order to explain these facts and the orderly progression of our weather, it is necessary to look beyond our own narrow area to the surrounding continents and oceans.

If we take a chart showing the isobars for the eastern part of the northern hemisphere during January, a typical winter month (see Hann's Meteorological Atlas), we find that there is an area of markedly low pressure to the south-west of Iceland, while the pressures over the North Atlantic generally are low. At the same time the pressure is high over Asia, this belt of high pressure extending also over the greater part of the continent of Europe, except the north and extreme west, while another region of high pressure occurs in mid-Atlantic to the south-west of the Azores. It will be noted that much of the British area falls into the northern area of low pressure, while the southern part comes into the debatable area. As a result of this arrangement of isobars the prevailing wind is south-west, the winds whirling out of the mid-Atlantic area of high pressure into the Icelandic area of low pressure. We need not stop here to show that our characteristically mild winter climate is due to this predominance of warm winds in winter, but may repeat that this represents the mean condition. In point of fact our winter weather is determined by the constantly renewed conflict between cyclonic and anticyclonic conditions. The great area of high pressure over the continent of Europe and Asia is, as it were, constantly striving to spread itself over the British Islands, and when it succeeds we have calm, cold weather with slight precipitation, and sunshine or fog according to the local conditions. On the other hand, the Icelandic area of low pressure is constantly, as it were, throwing off moving areas of low pressure, or cyclones, and these travel with varying degrees of rapidity over one or other of the storm-tracks which cross the British Islands, and bring with them strong winds, relatively high temperature, and heavy rainfall. Now the passage of these cyclonic areas is favoured by an extension of the Icelandic area of low pressure over the northern part of Great Britain, and the result is that our winters swing between two types according to the extension of the areas of high and low pressure. If the continental area of high pressure encroaches upon our area we have the cold clear type; if the northern area of low pressure, the boisterous warmer type. If the details are complex this main fact is simple, and does not seem beyond the reach of even the school child.

If we now glance at a chart showing the distribution of pressure in July, we shall note some very marked differences in the position of the isobars. The area of low pressure in the vicinity of Iceland is no longer marked, but on the other hand the pressure has fallen greatly over the continent of Asia, now heated with the powerful summer sun. At the same time the region of high pressure in the Atlantic has become 
more northerly in position, and much more marked. The normal wind is now that of a more westerly type, which sweeps out of the Atlantic anticyclone towards the lower pressures in northern Europe and Asia, is cooler than the south-westerly wind of winter, and has thus a markedly tempering effect on the summer heat. The uniformity of this type is interrupted first by cyclones, which in summer are usually of a mild type, often bringing the summer rainfall in the shape of thunderstorms, and at other times marked by rain and moderate winds, but only rarely by storms. At other times, as already explained, our typical summer weather is interrupted by anticyclones, producing unusual heat and drought, and lasting until displaced by some minor cyclonic disturbance from the west. Such is the usual trend of British weather throughout the year, markedly regular in its irregularities. A few words may, however, be said as to the spring. In the region of Aberdeen, as over Great Britain generally, the highest mean barometric pressures occur in spring, especially in April and May, the period also when the gradient is least. This means that in these months the weather is predominantly anticyclonic, cyclones being of minor importance. Therefore, for the reasons already explained, this is the time when we tend to have cold, dry, disagreeable east winds, but it should be clearly understood that it is largely their anticyclonic character that gives these winds their unpleasant qualities. All the characters of anticyclonic weather are often well shown in spring. We have the clear sky, with fog in valleys, especially in the evenings and mornings, the bitter dry wind, the warm sun, and the sudden drop of temperature when the sun goes down.

My aim in this lecture has been both to show what there is to teach in connection with weather, and to suggest methods of teaching it. As is the case in practically all the sciences, the great difficulty is to combine in a rational way the method of direct observation and of instruction so as to give the taught something in the way of a practical appreciation of the subject. If I may recapitulate my suggestions, I should say begin first by the most general and simple observations of wind and sky, sunshine and rain. Then introduce the barometer, and get a series of observations sufficient to answer a series of questions, such as :does the barometer move or not? much or little? does the wind affect it? the temperature? rain? At first, at any rate, I should be disposed to let the class take observations for a school week at irregular intervals rather than continuously, and then let them compare different weeks until they gradually acquired some notion of the meaning of average height. After the interest had been aroused, it would be a good plan to give a series of more detailed lessons, and gradually introduce the consideration of cyclones and anticyclones, the reading of weather charts, and so forth. One would naturally take advantage of outstanding meteorological events as texts-a great storm such as that which wrecked the Berlin, a long frost, our late fine Easter : any one of these would form an interesting starting-point. As I have tried to show also, the subject may be correlated in many different ways with the ordinary geography lesson, or even with history, for climate has had much to do in making the British what they are, and climate is 
merely the average succession of weather. Especially, however, I should lay stress upon the attempt to employ meteorological phenomena as a stimulus to the imagination, and I should urge the value of introducing in occasional lessons conceptions which in their entirety may be beyond the reach of the class, but of which they can be made to understand enough to greatly interest them. I have great faith in Anatole France's dictum that a child's feelings may be intensely roused by subjects which are, strictly speaking, beyond his intellectual reach. I should strive to make clear, for instance, something of the romance of a meteorological map, to picture the many patient observers, widely separated from one another, who day by day records each his quota of facts-facts whose full significance the individual cannot at the time fully see, but which he registers in the certain knowledge that they will fit into a clear and coherent whole. Man now no more than ever he could can alter the the course of the winds, but within limits he has now so far conquered nature that he can tell whither they come and where they will go, he has conquered time and space so far that he can send warnings of coming changes. Here surely are facts which are worth knowing, suggestions which are worth making. Again, though the meteorological map is an extraordinary triumph of scientific skill, it has still many gaps. The meteorologist is still groping after that perfection of his methods which will enable him to prophesy without fear of error, and his science has not the frigidity of perfection, but the perennial interest of an evolving organism. In our own British weather maps so apparently a trifling matter as the opening of the cable to the Faeroes and Iceland has greatly increased the value of the forecasts.

I do not wish to claim for the study of the weather any monopoly of merit, but only to suggest that if I am right in my statement of the aims which should prompt the teacher of nature study, it is a branch which is well fitted to carry out these aims.

Teachers will find the following useful in connection with the study of weather: The chapters on British Weather and British Climates in Mackinder's Britain and the British Seas; Some Facts about the Weather, by Marriott; the publications of the Scottish Meteorological Society; of the Royal Meteorological Society; of the Mreteorological Office (cf. this Mragazine, p. 266), and also Symons's Meteorological MIagazine. The general subject is discussed in the ordinary text-books of meteorology, as Dickson's, Buchan's, Davis's, and others.

\section{PROCEEDINGS OF THE ROYAL SCOTTISH GEOGRAPHICAL SOCIETY.}

A MeEting of Council was held on the 12 th November, when the undermentioned ladies and gentlemen were elected Members of the Society :-

Charles Ker, M.A., C.A.

W. W. Naismith, C.A.

John Armour Brown.
Horace F. Munro.

Mrs. Malloch.

James W. Irummond. 